\title{
Surgical Management of Diabetic Foot: Clinical Study
}

\author{
Pallav Patel ${ }^{1}$, Mrugesh Chudasama ${ }^{2}$ \\ ${ }^{1}$ Associate Professor, Department of Surgery, GMERS Medical College, Vadnagar Gujarat, ${ }^{2}$ Assistant Professor, Department of Surgery, GMERS Medical \\ College, Vadnagar Gujarat.
}

\section{Abstract}

Background: The term diabetic foot infection comprises many different entities that span a continuum of infectious processes. Aim of the present study was to analyze the risk factors leading to complication in diabetic foot infection and to study the outcome of treatment modalities of the diabetic foot. Subjects and Methods: A total of 100 cases were included in the study. The present study was undertaken with the aim to find out the clinical presentation, management, prevention, aetiology and surgical complications of the infection in the foot of diabetic patients. Results: The diabetic foot was found in the middle aged group persons usually in 4th and 5th decade. There were 50 males and 50 females of which $70 \%$ patients had symptoms of diabetic foot ulcer, $20 \%$ patients had diabetic foot cellulites, $10 \%$ of patients presented with gangrene diabetic foot. The surgical site infection was the most common complications accounting for total of 10 patients. Conclusion: Now the aim of surgical management of the diabetic foot is conservation. Diabetic foot is one of the most difficult infections to treat as it involves systemic diseases, lower resistance, ignorance in part of patients, and poor compliance of long term insulin therapy and fear of surgery in part of patients.

Keywords: Complications, Diabetic foot, Surgery, Foot ulcers.

Corresponding Author: Dr Mrugesh Chudasama, Department of Surgery, GMERS Medical College, Vadnagar Gujarat.

Received: May 2019

Accepted: June 2019

\section{Introduction}

Over time, diabetes can damage your nerves or blood vessels. Foot can be lost from the nerve damage due to diabetes. ${ }^{[1]}$ You may not feel a cut, a blister or a sore. Compromise of the blood supply from microvascular disease, often in association with lack of sensation because of neuropathy, predisposes persons with diabetes mellitus to foot infections. These infections span the spectrum from simple, superficial cellulitis to chronic osteomyelitis. Wounds of the foot are the most common reason for diabetes-related hospital admissions. In many of these cases, surgical intervention is the best option. ${ }^{[2]}$

Presence of several characteristic diabetic foot pathologies such as infection, diabetic foot ulcer and neuropathic osteoarthropathy is called diabetic foot syndrome. ${ }^{[3]}$

Globally, diabetes mellitus has grown to pandemic proportions, affecting 194 million people worldwide and is expected to increase in prevalence to 344 million by the year 2030. Of these patients, between 2 and $6 \%$ will develop a diabetic foot ulcer yearly. ${ }^{[4,5]}$

Infections in patients with diabetes are difficult to treat because these individuals have impaired microvascular circulation, which limits the access of phagocytic cells to the infected area and results in a poor concentration of antibiotics in the infected tissues. ${ }^{[6]}$

Diabetic foot infections range from local fungal infections of the nails to necrotizing limb- or life-threatening infections.
The term diabetic foot infection comprises many different entities that span a continuum of infectious processes. ${ }^{[7]}$ Cellulites and minor web-space infections may progress more rapidly in diabetics due to the combination of immune dysfunction and delayed detection secondary to diabetic neuropathy and retinopathy. Clinical signs of infection may not manifest until the infection is advanced. The typical bacterial pathogens encountered vary with the Wagner grade and severity of infection. Early infections are generally monomicrobial, whereas advanced infections tend to be polymicrobial. ${ }^{[8]}$

Keeping the above points in mind aim of the present study was to analyze the risk factors leading to complication in diabetic foot infection and to study the outcome of treatment modalities of the diabetic foot.

\section{Subjects and Methods}

A total of 100 cases were included in the study. The present study was undertaken with the aim to find out the clinical presentation, management and surgical complications of the infection in the foot of diabetic patients.

All the patients included in the study were informed about the study and on their willingness only they were asked to sign the inform consent. Only those patient who signed the inform consent were included in the study. The ethical committee of the medical institute was consulted and approval was taken before the conduction of the study. 
Detailed history was recorded for all the patients and any previous history related to the diabetes, wound healing, ulcers and boils in other part of the body were recorded.

All the patients were evaluated for the general physical and local examination as well as systemic examination, Wagner's classification; Operative characteristics included: type of operations performed and post- operative complications. Routine blood examination, blood sugar test, urine sugar test, $\mathrm{x}$ ray of the part involved, culture \& sensitivity of the discharge from the infection were also done. Data were collected using a designed questionnaire. Data collected were analyzed using SPSS computer software 15.0. The test statistics used included student's t test and Chi squared test. The student's t test was used to test for differences between quantitative variables and Chi squared test was used to test for associations and comparisons of proportions. Significance was defined as a p-value of less than 0.05 .

\section{Results}

A total of 100 patients were included in the study. All the patients were with the age between 40 years to 60 years. The mean age was 55.39 years. The higher incidence of diabetic foot lesions in male due to the unhygienic foot care, trauma, smoking and other unwanted habits. There were 50 males and 50 females of which $85 \%$ of patients belong to low socioeconomic status. All the majority of the patients came from the rural areas located at some distance areas from the medical institute. The diabetic foot was found in the middle aged group persons usually in 4 th and 5 th decade.

Out of the total 100 patients who were included in the study, $10 \%$ of patients presented with gangrene diabetic foot, $20 \%$ patients had diabetic foot cellulites, $70 \%$ patients had symptoms of diabetic foot ulcer,

Twenty percent of population had family history of diabetes mellitus. Smoking, tobacco chewing and alcohol use was reported in at least $40 \%$ of the total patients admitted for treatment. Staphylococcus aureus was isolated in $55 \%$ of the cases of diabetic foot infection, gram negative organisms in $25 \%$ of cases, beta haemolytic streptococci were isolated in $8 \%$ of the total cases, anaerobic cocci was found in $10 \%$ of cases.

Of the total admitted patients, 39 of them where newly diagnosed diabetic patients. Majority of them had type 2 diabetes mellitus. Maximum numbers of patients were presented between 8 weeks to 30 weeks of onset of ulcer. Twenty five patients had previous history of foot ulcers and 10 patients had previous history of amputation.

Viewing to the treatment part, $26 \%$ patients were treated conservatively with daily dressing and antibiotics, whereas $74 \%$ patients were treated surgically. Most of the patients who were treated surgically underwent lower limb amputation in $60 \%$ of cases. On owing to the severity of the ulcer, patients with gangrenous characteristics were amputed as compared to

The mean length of hospital stay was 5 weeks on average depending on one's individual recovery capability A total of 20 post operative complications were recorded in 50 patients. The surgical site infection was the most common complications accounting for total of 10 patients. Complications rate was significantly high in the patients who had major lower limb amputations.

Table 1: Age incidence of patients with diabetic mellitus

\begin{tabular}{|l|l|l|}
\hline Sr. No. & Age Group & Number \\
\hline 1 & $40-50$ years & 50 \\
\hline 2 & $51-60$ years & 50 \\
\hline 3 & Total & 100 \\
\hline
\end{tabular}

Table 2: Distribution of types of Presentation

\begin{tabular}{|l|l|l|}
\hline Sr. No. & Types of Presentation & No. of cases \\
\hline 1 & Ulcer & 75 \\
\hline 2 & Cellulites & 15 \\
\hline 3 & Gangrene & 15 \\
\hline 4 & Total & 100 \\
\hline
\end{tabular}

Table 3: Common bacteria isolated those with non-gangrenous characteristics.

\begin{tabular}{|l|l|l|}
\hline Sr. No. & Name of Organism & Percentage of cases \\
\hline 1 & Staphylococcus aureus & $55 \%$ \\
\hline 2 & Gram Negative Organisms & $25 \%$ \\
\hline 3 & Beta Haemolytic Streptococci & $8 \%$ \\
\hline 4 & Anaerobic Cocci & $10 \%$ \\
\hline
\end{tabular}

Table 4: Types of operations performed $(n=100)$

\begin{tabular}{|l|l|}
\hline Type of operation & Frequency \\
\hline Debridement & 25 \\
\hline Amputation & 60 \\
\hline Skin Grafting & 5 \\
\hline Incision \& Drainage & 4 \\
\hline Sequestrectomy & 6 \\
\hline
\end{tabular}

Table 5: Wagner's classification of diabetic foot ulcers

\begin{tabular}{|l|l|l|}
\hline Sr. No. & Ulcer Grading & Description \\
\hline 1 & Grade 0 & No ulcer but high risk foot \\
\hline 2 & Grade 1 & Superficial ulcer \\
\hline 3 & Grade 2 & $\begin{array}{l}\text { Deep ulcer, no bony involvement or } \\
\text { abscess }\end{array}$ \\
\hline 4 & Grade 3 & Abscess with bony involvement \\
\hline 5 & Grade 4 & Localized gangrene eg. toe, heel, etc \\
\hline 6 & Grade 5 & $\begin{array}{l}\text { Extensive gangrene involving the whole } \\
\text { foot }\end{array}$ \\
\hline
\end{tabular}

\section{Discussion}

Foot ulcers frequently become infected, with potentially disastrous progression to deeper spaces and tissues. Foot complications are common among diabetic patients; foot ulcers are among the more serious consequences. If not treated promptly and appropriately, diabetic foot infections can become incurable or even lead to septic gangrene, which may require foot amputation. ${ }^{[9]}$ Specimens for culture should be obtained after wound debridement to avoid contamination and optimise identification of pathogens. Diabetic foot lesions are commonly found in the middle aged person usually in to the 4 th and 5 th decade of their life. ${ }^{[9,10]}$

Sensory neuropathy and impaired proprioception decrease the foot's ability to adapt to repetitive local stresses and resultant ulcers tend to progress unnoticed in the insensate foot. Studies in Netherlands and Iran found high prevalence of $20.0 \%$ and $20.4 \%$ respectively. These differences in prevalence may be a reflection of regional variations in prevalence of diabetes mellitus and the local operating risk 
factors of diabetic foot ulcer disease. ${ }^{[7]}$

Morbach et al, ${ }^{[11]}$ compared foot disease in Germany, India and Tanzania and found that German patients were significantly older compared with those from Tanzania and India. These studies were conducted in different centres that offer diabetes care of different qualities. This comparable mean age may suggest certain time-dependent risk factors in the evolution and course of diabetic foot ulcer disease which are common to diabetes in whatever environment. Age of onset of diabetes is also different in continents.

In our present study, males were found to be more affected than females which are in agreement with other studies. Male predominance may be attributed to their smoking habits which were recorded in $35.3 \%$ of cases. Wound debridement, slough excision, followed by dressing with povidine-iodine, metronidazole, collagenase, L- lysine, mupirocin, dressings resulted in healing of ulcers. Split skin grafting, disarticulation, bellow knee amputation, and above knee amputation, were the other modes of treatment. ${ }^{[12]}$ Wong et al. reported $87 \%$ success rate in limb salvage after using repeated 'piecemeal' debridements and herbal drinks. Dressing materials used include saline-soaked gauze dressings; moisture retaining dressings, optimize the wound environment and promote healing.

The majority of patients in the present study presented to the surgical department between four weeks and 52 weeks (median of 18 weeks) of onset of an ulcer. Similar observation was also reported by other studies. Late presentation in our patients may be attributed to low socioeconomic status, poverty, lack of diabetes education (regarding the importance of general foot care, the significance of diabetes and its complications), unrecognized foot trauma from walking barefoot and lack of access to medical care. Other contributing factors for late presentation include attempts at home surgery, trust in faith healers and undetected diabetes.

\section{Conclusion}

Surgical management of diabetic foot has changed drastically over a period of time. Now the aim is conservation. The awareness of surgical complication of diabetic foot has helped in reducing dreaded complications like gangrene in some of the patients. Diabetic foot is one of the most difficult infections to treat as it involves systemic diseases, lower resistance, ignorance in part of patients, and poor compliance of long term insulin therapy and fear of surgery in part of patients.

\section{References}

1. Said G: Diabetic neuropathy-a review. Nature clinical practice Neurology 2007, 3:331-40.

2. Besse J-L, Leemrijse T, Deleu P-A: Diabetic foot: the orthopedic surgery angle. Orthopaedics \& Traumatology: Surgery \& Research 2011, 97:31429 .

3. Delbridge L, Ctercteko G, Fowler C, Reeve T, Le Quesne L: The aetiology of diabetic neuropathic ulceration of the foot. British Journal of Surgery 1985, 72:1-6.

4. Shapiro J, Nouvong A: Assessment of Microcirculation and the Prediction of Healing in Diabetic Foot Ulcers: INTECH Open Access Publisher, 2011.

5. Shapiro J, Koshimune D, Moellmer R: Diabetic Foot Ulcers-Treatment and Prevention. Open Access distributed under the Creative Commons Attribution 2013, 3

6. Ansari M, Shukla V: Foot infections. The international journal of lower extremity wounds $2005,4: 74-87$.

7. Adams Jr CA, Deitch EA: Diabetic foot infections. 2001

8. Neville RF, Roberts AD, Simon GL: Diabetic Foot Infection. Essentials of Vascular Surgery for the General Surgeon: Springer, 2015. pp. 71-81.

9. Armstrong DG, Lipsky BA: Diabetic foot infections: stepwise medical and surgical management. International Wound Journal 2004, 1:123-32.

10. Kosinski MA, Lipsky BA: Current medical management of diabetic foot infections. Expert review of anti-infective therapy 2010, 8:1293-305.

11. Morbach S, Lutale J, Viswanathan V, Möllenberg J, Ochs H, Rajashekar S, Ramachandran A, Abbas Z: Regional differences in risk factors and clinical presentation of diabetic foot lesions. Diabetic Medicine 2004, 21:91-5.

12. Parker PJ: Kosovo 1999-A Surgical Template for Modern Conflict. Journal of the Royal Army Medical Corps 2000, 146:199-203.

Copyright: (C) the author(s), 2019. It is an open-access article distributed under the terms of the Creative Commons Attribution License (CC BY 4.0), which permits authors to retain ownership of the copyright for their content, and allow anyone to download, reuse, reprint, modify, distribute and/or copy the content as long as the original authors and source are cited.

How to cite this article: Patel P, Chudasama M. Surgical Management of Diabetic Foot: Clinical Study. Acad. J Surg. 2019;2(1):4-6.

DOI: dx.doi.org/10.21276/ajs.2019.2.1.2

Source of Support: Nil, Conflict of Interest: None declared. 